\title{
Co-pelletization of Industrial Sewage Sludge and Rice Straw: Characteristics and Economic Analysis
}

\author{
Krittidej Duangjaiboon ${ }^{a}$, Mettaya Kitiwan $^{b}$, Prangthip Rittichote Kaewpengkrowa* \\ ${ }^{a}$ Rattanakosin College for Sustainable Energy and Environment (RCSEE), Rajamangala University of Technology Rattanakosin, \\ 96 Moo 3 Phutthamonthon Sai 5 Rd., Salaya, Phutthamonthon, Nakhon Pathom, 73170, Thailand. \\ ${ }^{b}$ Faculty of Science, King Mongkut's Institute of Technology Ladkrabang, Chalongkrung Rd., Ladkrabang, Bangkok 10520, \\ Thailand.
}

\begin{abstract}
The disposal of industrial sewage sludge is one of the most serious environmental problems in Thailand. Moreover, the disposal expense is considered as the production cost to the manufacturer. Therefore, the concept of waste-to-energy technology (WTE) is applied to solve this problem. This study aimed to study the effect of sewage sludge and rice straw proportions on the properties of copellets. Here, the production of co-pelleted sewage sludge from the canned food industry, combined with biomass (rice straw), was performed using a lab-scale pelletization machine. The pellets consisted of sewage sludge (SS) and rice straw (RS) with sewage sludge ratios of RS100:SS0, RS50:SS50, RS35:SS65, RS25:SS75, and RS0:SS100. The co-pellets produced were characterized for physicochemical properties and calorific heating values. In addition, the benefit to cost ratio (B/C), internal rate of return (IRR), and payback period (PB) from the utilization of co-pellets were studied. The results suggest that the proportion of sewage sludge affects the properties of the copellets. The optimum sewage sludge to rice straw ratio at RS0:SS100 is considered to have good fuel combustion properties. It is suitable for the production of co-pellets because of its high volatility and low ash slagging content.
\end{abstract}

Keywords: co-pellets, pelletization, sewage sludge, waste to energy, rice straw

Article History: Received: 30 ${ }^{\text {th }}$ Oct 2020; Revised: 27 ${ }^{\text {th }}$ Feb 2021; Accepted: $1^{\text {st }}$ April 2021; Available online: $15^{\text {th }}$ April 2021

How to Cite this Article: Duangjaiboon, K., Kitiwan., M., and Kaewpengkrow, P.R. (2021) Co-pelletization of industrial sewage sludge and rice straw: an environmental and economic analysis. International Journal of Renewable Energy Development, 10(3),653-662 https://doi.org/10.14710/ijred.2021.33834

\section{Introduction}

The canned tuna processing industry is very important for the economic development of Thailand. Exporting canned tuna to more than ten countries generates a high income for Thailand. The aim to ship USD 2,501.9 million by 2019 reflects the high growth of the industry. The development of the canned tuna industry in the country has increased, and its production processes produce waste in solid and liquid forms. This large-scale waste requires appropriate handling.

Sewage sludge (SS) is collected from sludge residue dewatering at wastewater treatment plants (WWTPs). It treats wastewater from households, public facilities, and industries. Normally, SS is a heterogeneous mixture of non-degradable organic matter comprising microorganisms, such as plant residues, paper waste, oils, and food waste, water, and inorganic components that comprise more than $50 \%$ of the sewage sludge. The nondegradable organic matter in sewage sludge includes different hydrocarbon compounds, namely, lipids, carbohydrates, proteins, peptides, phenolics, aliphatic hydrocarbons, and polycyclic aromatic hydrocarbons (Racek et al., 2020).

There is little information on the contents of sewage sludge from canned tuna wastewater. Guerard et al.
(2002) studied liquids and solid wastes that were more than $50 \%$ of the raw material, including skin waste, viscera, bones, fins, and blood that are generated from canned tuna processing. Sultanbawa et al. (2006) and Hsu et al. (2009) studied the canned tuna industry's processing discards. The waste was $50-55 \%$ of the raw material generated during loin preparation and the tuna cooking juice comprised approximately $4 \%$ of is waste from canned tuna processing. The demand for chemical oxygen (COD) increases with an increase in the amount of waste in the wastewater, and researchers have reported waste utilization (by-product) derived from canned tuna using various processes. The present study focuses on the utilization of sewage sludge from WWTPs that requires disposed to produce co-pelleted fuel.

Sewage sludge must be treated to reduce waste and add to the value of waste by producing fishmeal for animal feed. However, the amounts of liquid waste and remaining solids are high. These wastes pass through the wastewater treatment system to treat and separate the sediment sludge from the wastewater (Huang et al., 2017; Zhou et al., 2020), improving the water quality before it is released to the community (Fig. 1). However, the separated sewage sludge from wastewater treatment cannot be utilized. Generally, the sewage sludge collected is sent to a treatment facility for disposal by stabilization and secure 
landfill. The disposal cost of the waste generated from the industries needs to be considered. Sewage sludge from wastewater treatment plants is an organic waste that commonly comprises a high amount of nitrogen and phosphorous and concentrations of micronutrients (Huang et al., 2017).

Rice is a significant crop in south and South-East Asia, including Thailand, and as such, a large amount of rice straw residue (approximately 740.95-1,111.42 million ton/yr) is produced (Abraham et al., 2016). Currently, rice straw is often disposed of by open burning, which significantly increases environmental pollution. It is generally composed of a heterogeneous complex of carbohydrate polymers that are suitable as a substitute for solid fuel (Park et al., 2014; Huang et al., 2017), and consequently, a significant amount of rice straw is applied to biofuel, which can reduce greenhouse gas (GHG) emissions derived from open burning.

Waste-to-energy (WTE) is one of the most important options for obtaining energy recovery from industrial waste and municipal solid waste, and these wastes are considered for utilization from waste to energy. The process of valorizing sewage sludge has been investigated, including the production of pyrolysis oil from sewage sludge, the production of biochar and activated carbon, and the utilization of sewage sludge combustion ash in cement and other materials (Huang et al., 2017; Kowalski et al., 2018; Zhu et al., 2019; Krueger et al., 2020; Kwapinska et al., 2020). Thermochemical processes, such as combustion, gasification, pyrolysis, co-pyrolysis, and catalytic pyrolysis for energy, thermal processes, and resource recovery from sewage sludge residue are of research interest (El-Qelish et al., 2019; Grobelak et al., 2019; Gao et al., 2020; He et al., 2020). Furthermore, sewage sludge from industrial wastewater could produce briquette fuel to replace biofuel in boilers.

Generally, sewage sludge from wastewater has a low calorific value (8.00-11.00 $\mathrm{MJ} / \mathrm{kg}$ ), and the solid fuel produced from it is economically unfavorable. He et al. (2020) and Hossain et al. (2020) investigated the performance of sewage sludge from wastewater for direct combustion in the production of energy and heat, and others have explored upgrading sewage sludge by pelletization because it reduces volume and has high energy density compared to material feedstocks

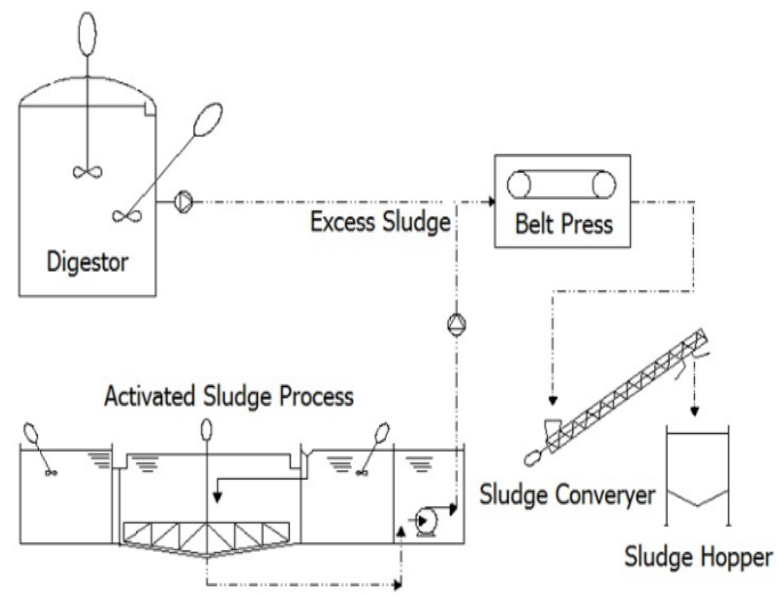

Fig. 1 Sewage sludge from canned tuna wastewater treatment processing
Therefore, pellets are more efficient in terms of storage, energy conversion, and transportation. Hossain et al. (2020) examined the characteristics of the biofuel properties of microalgae, sewage sludge, and various proportions of this waste combined with coal. The sample proportion of microalgae, sewage sludge, and coal was 25 : 25: 50 , showing the highest density of pellets $\left(1.23 \mathrm{~g} / \mathrm{cm}^{3}\right)$ and energy density $\left(20.41 \mathrm{GJ} / \mathrm{m}^{3}\right)$, which is the most favorable property of co-pelleted for applications in transportation and logistics. Fu et al. (2012), Hossain et al. (2020), and Lisowski et al. (2020) also investigated the physicochemical characteristics of pellets from the blended shredded biomass of hay and wheat straw. According to previous studies, processing and pelletizing other biomass wastes and the mixing of waste is difficult. To substitute solid fuel, the pelletization of light agricultural waste to form compressed pellets for use as a solid biofuel in a combustor/boiler may offer a solution.

One advantage of pellets is the shrinkage of their original sizes after extrusion, which increases the utilization of solid biomass fuels in terms of storage, logistics handling, and transportation (Jiang et al., 2014). Moreover, the co-pellets can be stored safely without the risk of subordinate environmental pollution and can be transported easily, and as such, biomass pellets can reduce the costs of handling, transportation, and storage. The most compelling method for improving the combustion performance of sewage sludge is sludge mixing with auxiliary fuel, such as coal, refuse, sawdust, and other biomass.

Yilmaz et al. (2018) studied the key factors affecting the co-pelletization conditions of sewage sludge and agricultural residues. The production of pellets using waste or residue materials such as straw, rice husks, bagasse from sugar cane, furniture industry waste, and wood waste has been reported in other studies (Jiang et al., 2016). Several parameters and variables affect the pelletization process and the material characteristics of the pelleted product, namely, the physical, chemical, and mechanical properties (Scatolino et al., 2018).

The pelletization of agricultural waste could also provide an alternative to solve the problem of agro-waste management and make it a possible income source for local farmers (Pradhan et al., 2019). However, few studies have compared the ratios of biomass and their blends for pellet production, combined with economic feasibility. When considering the agricultural waste problem in Thailand, the disposal of rice straw, which is the main agricultural waste, needs to be urgently addressed. Using rice straw, in combination with sewage sludge as fuel pellets, would be an alternative option for eliminating agricultural waste and increasing the energy properties of fuel pellets. To further develop the sustainable energy conversion of sewage sludge, the co-pelletization of sewage sludge and rice straw at various ratios has been comprehensively investigated by physiochemical analysis. Dessbesell et al. (2019) conducted a risk assessment and economic analysis of a wood pellet plant at a sawmill in the Rio Pardo Watershed in Brazil and found that the mill wood pellets could be used as an energy source for farms. In an environmental analysis, Saosee et al. (2020) used a Life Cycle Assessment (LCA) of electricity production in Thailand to compare fossil fuels and wood pellets and found that in terms of quality, resource scarcity, ecosystems, and human health, using wood pellets as a 
fuel for electricity generation was superior to fossil fuels. Nagy et al. (2018) studied the economics of a process to produce pellets for utilization in a biogas plant and found that the pelleted $(6 \%-10 \%)$ dry matter substrate content was produced at a cost of 88-90 EUR/ton.

This study aimed to produce co-pellets from rice straw and sewage sludge and investigate the proportion of copelleted rice straw and sewage sludge. The physical properties, calorific values, economics, and environmental implications of the utilization of co-pellets were analyzed. The results of this study can be used to develop sustainable energy conversion of sewage sludge and biomass utilization for energy recovery. The greatest advantage in reducing waste disposal costs and recovering this waste into energy is the reduction in energy costs for industries.

\section{Materials and Methods}

To prepare and improve the properties suitable for testing, sewage sludge from canned tuna WWTPs was required.

\subsection{Sewage sludge collection and preparation}

The sewage sludge from the canned tuna industry in Thailand was dewatered using a sludge dewatering machine (Belt press). The SS was sun-dried for two days and stored at $4{ }^{\circ} \mathrm{C}$ before characterization and pelletization. However, the moisture content after sundrying remained higher than $30 \%$ wt. Therefore, the sludge samples were dried in an oven at $105^{\circ} \mathrm{C}$ for $1 \mathrm{~h}$. The samples were then blended into five different ratios by weight of sewage sludge to rice straw (RS100:SS0, RS50:SS50, RS35:SS65, RS25:SS75, and RS0:SS100). Characterization was conducted according to the American Society for Testing and Materials (ASTM) methods (testing for proximate analysis).

\subsection{Rice straw preparation}

The rice straw (RS) was obtained from a farm in Nakornphathom Province, Thailand. First, all feedstock samples were dried in air for $2 \mathrm{~d}$, and the particle size was reduced to 1-2 mm using a lab-scale crusher. The samples were then dried in an oven at $105{ }^{\circ} \mathrm{C}$ for $24 \mathrm{~h}$ and finally stored in jars at room temperature. The milled rice straw was used as biomass for mixing with the sewage sludge at various weight proportions for $1 \mathrm{~h}$ before pelletization with SS.

\subsection{The characterization of sewage sludge and rice straw}

The sludge and rice straw samples were used as raw materials for compressed fuel bars and were analyzed for essential components using the following four methods:

\subsubsection{Proximate analysis}

A proximate analysis was conducted according to the ASTM standard to classify the samples in terms of moisture content (ASTM E871), fixed carbon (ASTM E872), volatile matter (ASTM E872), and ash content (ASTM D1102). Elemental composition and thermal behaviors were determined using a Leco TruSpec ${ }^{\circledR}$ CHNO (micro).

\subsubsection{Calorific value}

The calorific value of the sludge samples and rice straw were analyzed using a bomb calorimeter (IKA-C6000). Calorific value is measured by the amount of heat released when combustion occurs completely. The sample was contained in the support and stimulated by oxygen under high pressure. Increasing the water temperature shows the amount of heat released from the sludge sample, which conforms to ASTM D 5865.

\subsubsection{Fourier Transform Infrared Spectrophotometer (FTIR)}

Fourier-transform infrared spectroscopy (FTIR) was important for identifying the samples and studying the structures of the sewage sludge and straw molecules using infrared adsorption. The functional groups of sewage sludge and rice straw were characterized using FTIR (Perkin Elmer, Spectrum100, Waltham, USA). A spectrometer in transmittance mode, with scanning frequencies from 4,000 to $600 \mathrm{~cm}^{-1}$, was used to determine their functional groups resolution of $4 \mathrm{~cm}^{-1}$.

\subsubsection{Thermogravimetric Analyzer (TG/DTG)}

A thermogravimetric analysis was performed to determine the thermal degradation profile of the sewage sludge using a thermogravimetric analyzer (Perkin Elmer, Pyris1, Waltham, USA). The analysis was performed at $30-1,000{ }^{\circ} \mathrm{C}$ at a heating rate of $10^{\circ} \mathrm{C} / \mathrm{min}$.

\subsection{Process of co-pelletization}

The pelletization procedure was simulated on a laboratory scale machine at a loading rate of $1-5 \mathrm{~kg} / \mathrm{h}$, depending on the biomass properties pressed using high-compress cold compression. Compression causes the raw material molecules and polymer chains to aggregate and bond, and it is not necessary to grind the raw materials before compacting if the raw materials are smaller than $10 \mathrm{~mm}$. The rice straw was crushed to a particle size of $1-2 \mathrm{~mm}$ using a grinder (Fig. 2). The sludge and rice straw samples were firstly prepared by controlling the moisture content of the mixed material to less than $20 \% \mathrm{wt}$.

The rice straw samples were mixed with sewage sludge that was dehydrated to extrusion following the specified proportion of sewage sludge as RS100:SS0, RS50:SS50, RS35:SS65, RS25:SS75, and RS0:SS100\%wt. using an inhouse pelletization machine (Fig. 3). The material was prepared using the pellet mill of an in-house pelletization machine. The prepared pellets were approximately $6 \mathrm{~mm}$ in diameter. The addition of sewage sludge to the rice straw facilitates compression and extrusion, resulting in reduced energy input.

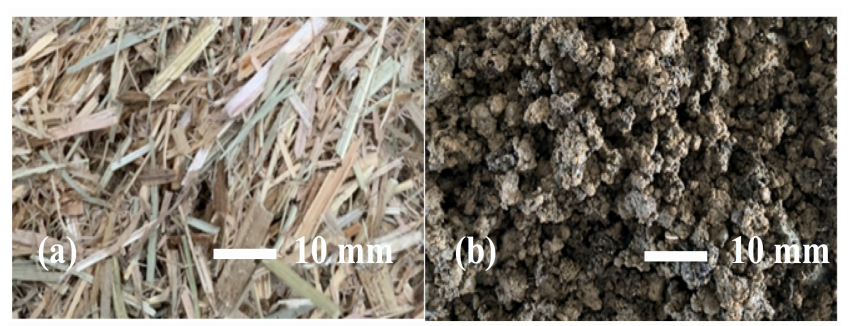

Fig. 2 Raw materials (a) sewage sludge and (b) biomass of rice straw 
Pelletized biomass is a significant parameter for transportation and logistics purposes. An analysis of the proximate and calorific value of the co-pellets by the extruder followed the same methodology. However, the physical analysis of energy density, pellet density, and bulk density of the co-pellets required further investigation.

\subsection{Economic analysis}

An economic analysis of the production of co-pellets was estimated from the production of an in-house pelletization machine with a production capacity of $1 \mathrm{~kg} / \mathrm{h}$ and a service life of $10 \mathrm{y}$. The lab-scale pelletization machine had a manufacturing value of 20,650 THB (USD 688). The production cost consisted of energy for appliances and labor, with an average cost of $1 \mathrm{THB} / \mathrm{kg}$ (0.033 USD $/ \mathrm{kg})$. The material cost consisted of sewage sludge (no value) and rice straw of $0.2 \mathrm{THB} / \mathrm{kg}(0.0067$ USD $/ \mathrm{kg}$ ). The increasing proportion of rice straw combined in the pellet fuel resulted in an increase in the cost of co-pelleted production.

The return of benefit from co-pelletization consisted of utilizing co-pellets instead of coal. This return depended on the mixing ratio of the co-pellets and the benefits from using sewage sludge as a material for the production of copellets.

The disposal cost of sewage sludge can be reduced by 1 $\mathrm{THB} / \mathrm{kg}$ (0.033 USD/kg). In the economic analysis based on a comparison, the costs and income over a set period can be summarized in terms of NPV, IRR, and B/C as indices for evaluation.

The NPV, according to the discount rate calculation method, is as follows (Zhao et al., 2016):

$N P V=\sum_{t=0}^{n} \frac{\text { Benefit-Cost }}{(1+i)^{t}}$.

The IRR, according to the calculation method is as follows:

$0=\sum_{t=0}^{n} \frac{\text { Benefit }}{(1+I R R)^{t}}-\frac{\text { Cost }}{(1+I R R)^{t}}$.

The $\mathrm{B} / \mathrm{C}$, according to the calculation method is as follows:

$B / C=\sum_{t=0}^{n} \frac{\sum_{t=0}^{n} \frac{\text { Benefit }}{(1+i)^{t}}}{\sum_{t=0}^{n} \frac{\text { Cost }}{(1+i)^{t}}}$.

Payback Period $=T-1+\frac{C N C F_{T-1}}{N C F_{T}}$,

where:

- $\quad \mathrm{NPV}$ is the net present value (THB)

- $\mathrm{B} / \mathrm{C}$ is the benefit per cost ratio (\%)

- $\quad$ IRR is the internal rate of return (\%)

- The benefit is the value of return in year $\mathrm{t}$ (THB)

- Cost is the value of cost in the year (THB)

- $\quad \mathrm{i}$ is the discount rate (assumed to be 0\%)

- $\mathrm{t}$ is the year,

- $\mathrm{n}$ is the number of years (yrs)

- $\mathrm{NCF}_{\mathrm{T}}$ is the net cash flow in the "T" years

- $\mathrm{CFCN}_{\mathrm{T}-1}$ is the cash flow of cumulative net in term the "T-1" years and

- $\mathrm{T}$ is the years when the cash flow of cumulative net is zero or positive.

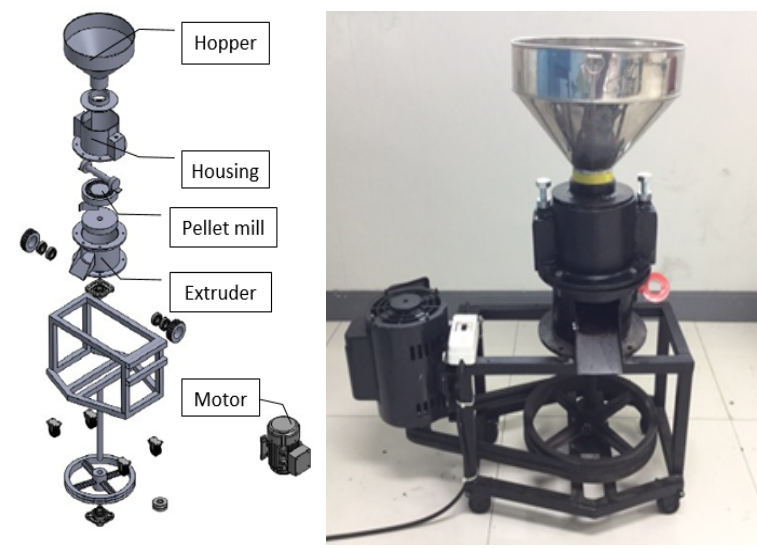

Fig. 3 In-house pelletization machine

\section{Result and discussion}

\subsection{The component characteristic of sewage sludge and rice straw}

\subsubsection{Proximate analysis}

The proximate analysis of rice straw and sewage sludge is presented in Table 1 . Fixed carbon and volatile substances are stored sources of solid fuel chemical energy, such as biomass. The index of gaseous biomass fuels is the volatile matter. Together, the combustible fraction of the fuel indicates that the value of the energy is fixed carbon and volatile matter. The sample analyzed sewage sludge and rice straw components compared to fossil fuels (coal), which is the most widely used fuel.

It was found that the properties of rice straw have a high volatile matter content of $74.40 \%$ (Table 1 ), which is similar to the findings of Biswas et al. (2018). The ash content of rice straw was $18.30 \%$, which was lower than that of sewage sludge, and the fixed carbon content of rice straw was low (7.30\%). The fixed carbon content of sewage sludge was low (4.87\%). Moreover, a high volatile content of sewage sludge $(60.98 \%)$ was obtained. The calorific value of sewage sludge $(11.84 \mathrm{MJ} / \mathrm{kg})$ was lower than that of rice straw (16.89 MJ/kg).

Table 1

The component characteristic of raw materials

\begin{tabular}{|c|c|c|c|}
\hline Rice straw & $\begin{array}{l}\text { Rice straw } \\
\text { (RS)* }\end{array}$ & $\begin{array}{c}\text { Sewage } \\
\text { Sludge } \\
\text { (SS)* }\end{array}$ & Coal \\
\hline \multicolumn{4}{|c|}{ Proximate analysis(wt.\%) } \\
\hline Moisture & $12.75( \pm 1.72)$ & $13.29( \pm 1.94)$ & $5.00-10.00$ \\
\hline Volatile matter & $74.40( \pm 1.17)$ & $60.98( \pm 1.58)$ & $25.00-40.00$ \\
\hline Ash & $18.30( \pm 1.24)$ & $20.86( \pm 1.38)$ & $8.50-11.30$ \\
\hline Fix carbon & $7.30( \pm 1.17)$ & $4.87( \pm 1.02)$ & $38.70-61.50$ \\
\hline \multicolumn{4}{|c|}{ Ultimate analysis(wt.\%) } \\
\hline $\mathrm{C}$ & $44.6( \pm 0.03)$ & $30.41( \pm 0.50)$ & $76.0-87.0$ \\
\hline $\mathrm{H}$ & $6.52( \pm 0.32)$ & $6.78( \pm 0.37)$ & $3.5-5.0$ \\
\hline $\mathrm{N}$ & $0.39( \pm 0.05)$ & $6.7( \pm 0.01)$ & $0.8-1.5$ \\
\hline $\mathrm{S}$ & $0( \pm 0.00)$ & $0( \pm 0.00)$ & $0.5-3.1$ \\
\hline HHV & 16.89 & 11.84 & $26.00-28.30$ \\
\hline
\end{tabular}

*dry basis (wt\%.) 


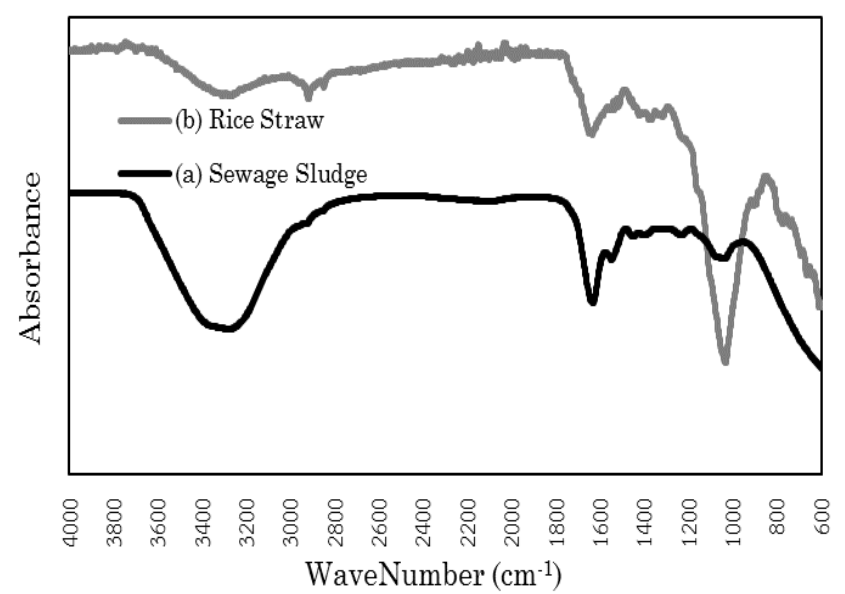

Fig. 4 FTIR spectra (a) sewage sludge and (b) biomass of rice straw

The final analysis was performed using a CHNS (micro) analyzer to examine components, such as hydrogen, carbon, nitrogen, oxygen, and sulfur (in weight percent), in the co-pellet samples. It was found that carbon (44.60 wt.\%) was the main element of this waste, which was similar to the general biomass pellets. However, one advantage of these wastes is non-sulfur contamination, which indicates that it is suitable for solid fuel production with non-sulfur gas by-products and high energy content. The nitrogen content in sewage sludge was higher than that of rice straw and other biomasses. Nitrogen is a precursor for $\mathrm{NO}_{\mathrm{x}}$ formation in fuel products, which may cause air pollution when used as a pellet fuel.

\subsubsection{Fourier Transform Infrared Spectrophotometer (FTIR)}

The analysis of the chemical structure from each condition using FTIR is shown in Fig. 5, and the signals at various wavenumbers are shown in Tables 2 and 3. Figure 4 shows the analysis of the structure of the raw materials for the pelleted fuel using the FTIR technique for the chromatogram of sewage sludge from the factory (Fig. 4a), and the chromatogram (Fig. 4b) is the information of rice straw. The graph in Fig. 4a shows the signal at a wavenumber of $3,678-2,678 \mathrm{~cm}^{-1}$ corresponding to the hydrogen-bonded alcohol structure, phenols, and carboxylic acids. This is similar to a previous study by Kim et al. (2013). It is estimated that this primarily arises from water. Moreover, the wavenumber signal at 1,782-1,482 $\mathrm{cm}^{-1}$ corresponds to the carbonyl structure expected from the cellulose composition. In addition, strong signals were found at wave numbers 1,160-980 $\mathrm{cm}^{-1}$, which corresponds to the carbonyl structure attributed to organic compounds such as cellulose and hemicellulose carbohydrates.

In the case of rice straw (Fig. 4b) Biswas et al. (2018) found that the wavenumber $3,447-3,143 \mathrm{~cm}^{-1}$ may be due to phenols forming intermolecular hydrogen bonds. Generally, the rice straw component mainly consists of cellulose and lignin. The wavenumber signals of 2,999$2,830 \mathrm{~cm}^{-1}$ correspond to the $\mathrm{C}-\mathrm{H}$ stretching of the alkyl structure, as expected from the composition of cellulose and hemicellulose. The wavenumber of 1,752-1,468 $\mathrm{cm}^{-1}$ was also found to correspond to the $\mathrm{O}-\mathrm{H}$ bending of the lignin structure. In addition, the majority of the wavenumber $1,644-1,385 \mathrm{~cm}^{-1}$ was found to conform to the structure of the signals of the carbonyl group, which can be characterized as organic compounds, namely, cellulose, hemicellulose carbohydrates, and lignin (Guzmán et al., 2015).

\subsubsection{Thermogravimetric Analyzer (TG/DTG)}

To understand the thermal behavior the thermal properties of the raw materials were studied by a thermogravimetric/differential thermal gravimetric analysis (TG/DTG). Figure 5a shows the thermal gravimetric of the sewage sludge curve, and the sewage sludge thermal decomposition was in the range of 50-700 ${ }^{\circ} \mathrm{C}$.

The relatively wide degradation range, followed by a rapid drop at $120{ }^{\circ} \mathrm{C}$, revealed that the sewage sludge contained a high water content. The sludge began to lose weight by water evaporation at temperatures of $84^{\circ} \mathrm{C}$ and $155^{\circ} \mathrm{C}$. In this step, the weight loss was significantly reduced, and the mass remained constant at $850{ }^{\circ} \mathrm{C}$. Therefore, this point is considered to be the end of the combustion.

Fig. 5 (b) shows the thermogravimetric analysis of rice straw. The mass of rice straw was lost from the evaporation of water at the temperature of $59.3^{\circ} \mathrm{C}$, and the mass decreased markedly to $259.6^{\circ} \mathrm{C}$. The mass of the straw decreased continuously until $551.7^{\circ} \mathrm{C}$, which is the end of the thermal degradation of rice straw. As a result of this study, this waste is recommended as a potential feedstock for pellet fuel.

Table 2

Functional groups of sewage sludge

\begin{tabular}{|c|c|c|c|}
\hline $\begin{array}{l}\text { Wavenu } \\
\text { mber } \\
\left(\mathrm{cm}^{-1}\right)\end{array}$ & Assignment & Characterization & References \\
\hline $\begin{array}{l}3,678- \\
2,678\end{array}$ & $\begin{array}{l}\mathrm{O}-\mathrm{H} \\
\text { stretching }\end{array}$ & $\begin{array}{l}\text { hydrogen-bonded } \\
\text { alcohols, phenols, } \\
\text { carboxylic acids }\end{array}$ & $\begin{array}{l}\text { (Kim et al., } \\
2013 \text { ) }\end{array}$ \\
\hline $\begin{array}{l}1,670-- \\
1,620\end{array}$ & $\begin{array}{l}\mathrm{C}=\mathrm{O} \\
\text { stretching }\end{array}$ & carbonyl groups & $\begin{array}{l}\text { (Kim et al., } \\
\text { 2013) }\end{array}$ \\
\hline $1,160-980$ & $\begin{array}{l}\text { C-O } \\
\text { stretching }\end{array}$ & $\begin{array}{l}\text { carbonyl groups } \\
\text { (alcohol, ester, } \\
\text { ether) }\end{array}$ & $\begin{array}{l}\text { (Kim et al., } \\
\text { 2013) }\end{array}$ \\
\hline
\end{tabular}

Table 3

Functional groups of rice straw

\begin{tabular}{llll}
$\begin{array}{l}\text { Wavenu } \\
\text { mber } \\
\left(\mathrm{cm}^{-1}\right)\end{array}$ & Assignment & Characterization & Reference \\
\hline $\begin{array}{l}3,447- \\
3,143\end{array}$ & $\begin{array}{l}\text { O-H } \\
\text { stretching }\end{array}$ & hydroxyl group & $\begin{array}{l}\text { (Biswas } \text { et al., } \\
2018)\end{array}$ \\
$\begin{array}{l}\text { 2,999- } \\
2,830\end{array}$ & C-H & alkyl group & $\begin{array}{l}\text { (Rungrodni } \\
\text { mitchai } \text { et } \\
\text { stretching }\end{array}$ \\
& al., 2014) \\
$1,752-$ & O-H bending & lignin & (Matthews, \\
1,468 & 2016) & \\
$1,644-$ & C-O & carbonyl groups & (Guzmán et al., \\
1,385 & stretching & & 2015) \\
\hline
\end{tabular}




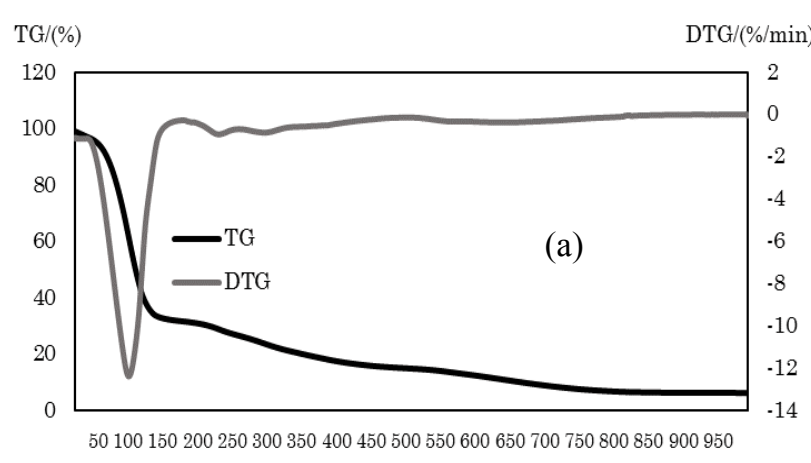

Temperature/( $\left.{ }^{\circ} \mathrm{C}\right)$

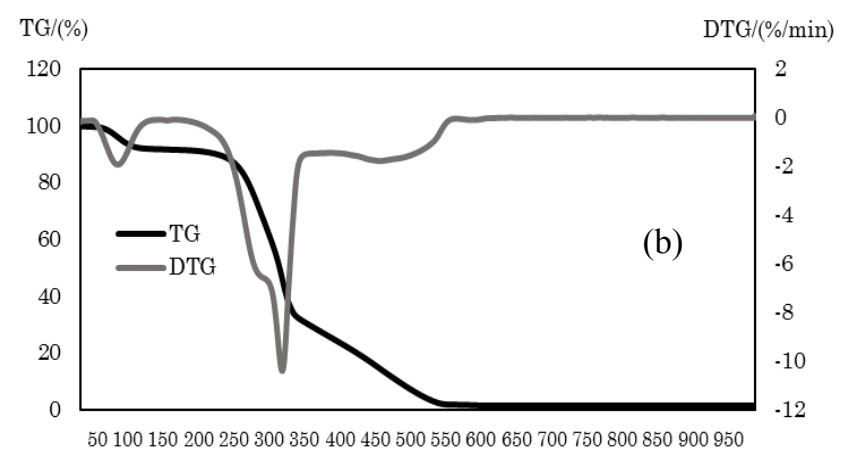

Temperature $/\left({ }^{\circ} \mathrm{C}\right)$

Fig. 5 TG-DTG analysis of (a) sewage sludge and (b) rice straw

Table 4

Characteristics of sewage sludge and rice straw co-pellets

\begin{tabular}{|c|c|c|c|c|c|}
\hline \multirow{2}{*}{ Parameter } & \multicolumn{5}{|c|}{ Rice Straw: Sewage Sludge (\%wt.) } \\
\hline & RS100: SS0 & RS50: SS50 & RS35: SS65 & RS25: SS75 & RS0: SS100 \\
\hline \multicolumn{6}{|c|}{ Proximate analysis (wt.\%) } \\
\hline Moisture & $5.50( \pm 1.75)$ & $21.68( \pm 1.72)$ & $33.56( \pm 1.94)$ & $40.12( \pm 1.80)$ & $47.91( \pm 1.64)$ \\
\hline Volatile matter & $86.02( \pm 1.65)$ & $65.48( \pm 1.45)$ & $52.06( \pm 1.36)$ & $43.26( \pm 1.67)$ & $37.38( \pm 1.59)$ \\
\hline Ash & $8.34( \pm 1.24)$ & $9.52( \pm 1.65)$ & $9.17( \pm 1.44)$ & $7.75( \pm 1.71)$ & $8.34( \pm 1.62)$ \\
\hline Fix carbon & $0.14( \pm 1.17)$ & $3.33( \pm 1.02)$ & $5.21( \pm 1.53)$ & $8.88( \pm 1.72)$ & $7.22( \pm 1.77)$ \\
\hline HHV (MJ/kg) & 18.42 & 16.22 & 15.70 & 15.38 & 15.13 \\
\hline LHV (MJ/kg) & 17.19 & 14.59 & 14.14 & 13.61 & 12.56 \\
\hline
\end{tabular}

(a) RS100:SS0

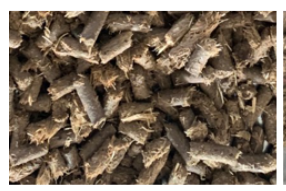

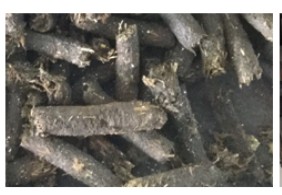

(d) RS25:SS75 (b) RS50:SS50

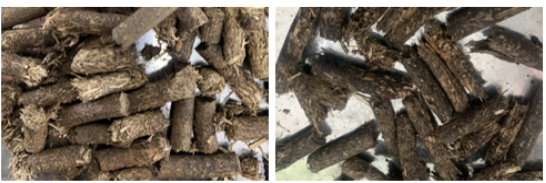

Fig. 6 Co-pellets in various proportions

\subsection{Co-pelleted characteristics}

The pelleted fuel was extruded into the bars in various proportions. The ratio of rice straw to sewage sludge was RS100:SS0, RS50:SS50, RS35:SS65, RS25:SS75, and RS0:SS100. The co-pelletization had approximate and average lengths of $6 \mathrm{~mm}$ and $25 \mathrm{~mm}$, respectively (Fig. 6).

Here, co-pellets were produced using an in-house pelletizer. The size of the co-pelleted samples was uniform for all samples (Fig. 6). This procedure differs from that of industry. Consequently, further research can be performed to apply several types of pelletization processes, namely, hydraulic press, extrusion, pellet mill, and screw pellet, of different sizes, to the characteristics of the produced pellets. The advantage of uniform and durable fuel pellets is that they minimize the amount of emissions during energy conversion (Pradhan et al., 2009). Moreover, the characterization of the feedstock in this study also focused on proximate analysis, particularly the ash content, to determine the probability of fouling and slugging in combustion. The TG analysis of all co-pelleted samples exhibited different thermal degradation phases of 50 to $900{ }^{\circ} \mathrm{C}$ at a heating rate of $10{ }^{\circ} \mathrm{C} / \mathrm{min}$. The results suggested that all pellets can be used as potential feedstock for biofuel purposes. The detailed physicochemical characteristics of co-pelleted samples with various $\mathrm{RS}$ and $\mathrm{SS}$ ratios, such as proximate analysis and calorific value, are listed in Table 4.

The ash content of co-pellets is relatively low (8.34$9.52 \%$ wt.) The high volatile organic matter content $(37.38-86.02 \%$ wt.) indicates that co-pellets could be promising candidates for solid fuel fabrication. The high moisture content should be removed from the co-pellets for the high-quality pellet formation process. However, the extremely high moisture content of the biomass significantly affects the combustion process, resulting in incomplete combustion (Hossain et al., 2020). However, the moisture in pelletization acts as both a binder and a 
lubricant. Water content acts as a film-forming binder with hydrogen bonding (Jiang et al., 2014). The results indicated that the optimization of pellet moisture should be less than $30 \%$. Moreover, the higher calorific value (HHV) of the co-pellets was in the range of 15.13-18.42 $\mathrm{MJ} / \mathrm{kg}$, and the lower calorific value (LHV) of the co-pellets was in the range of $12.56-17.19 \mathrm{MJ} / \mathrm{kg}$. These results concord with those reported previously (Yilmaz et al., 2018; Anna et al., 2019). The maximum calorific value was obtained from the pelleted RS100:SS0 (rice straw pellets) and was co-pelleted at a ratio of RS50:SS50.

Consequently, these co-pelleted materials can be used as raw materials for co-combustion, as substitutes for solid fuels. As shown in Table 4, the moisture content affects the extrusion of co-pellets because of the moisture content in the sewage sludge acting as a binder in the tissue bonding of matter. Therefore, a higher sewage sludge ratio resulted in easier extrusion of the co-pellets (RS25:SS75). Conversely, the high proportion of rice straw resulted in a lower moisture content of the co-pellet (RS50:SS50), which was difficult for co-pellet extrusion. Moreover, co-pellets with a higher sewage sludge ratio caused a high moisture content and low volatile matter values, which was the main reason for their lower calorific value. Therefore, the calorific value was analyzed for economic return, and it was found that the energy-saving costs were lower. This is because the high sewage sludge ratio of co-pellets can reduce the disposal costs when considering the total benefit. The results indicated that a higher sewage sludge ratio was a suitable proportion for pelletization.

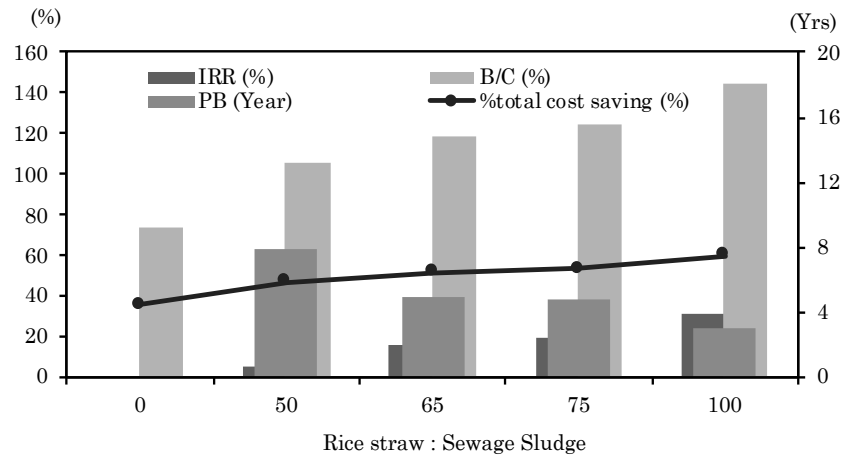

Fig. 7 Economic analysis of co-pelletization

Table 5

Investment costs, benefits, and analysis cost of co-pelletization

\begin{tabular}{|c|c|c|c|c|c|c|c|}
\hline \multirow{2}{*}{ Parameter } & \multicolumn{7}{|c|}{ Rice Straw: Sewage Sludge } \\
\hline & $\begin{array}{c}\text { RS100: } \\
\text { SS0 }\end{array}$ & $\begin{array}{l}\text { RS50: } \\
\text { SS50 }\end{array}$ & $\begin{array}{l}\text { RS35: } \\
\text { SS65 }\end{array}$ & $\begin{array}{l}\text { RS25: } \\
\text { SS75 }\end{array}$ & $\begin{array}{c}\text { RS0: } \\
\text { SS100 }\end{array}$ & Coal & Unit \\
\hline Manufacture Capacity & 8,760 & 8,760 & 8,760 & 8,760 & 8,760 & 8,760 & $\mathrm{~kg} / \mathrm{Yrs}$. \\
\hline Investment Costs & 20,650 & 20,650 & 20,650 & 20,650 & 20,650 & - & THB \\
\hline Material Costs & 0.20 & 0.10 & 0.07 & 0.05 & 0.00 & 3.00 & $\mathrm{THB} / \mathrm{kg}$ \\
\hline Operating Costs & 1.00 & 1.00 & 1.00 & 1.00 & 1.00 & 0.00 & $\mathrm{THB} / \mathrm{kg}$ \\
\hline Net Heating Value & 17.19 & 14.59 & 14.14 & 13.61 & 12.56 & 27.79 & $\mathrm{MJ} / \mathrm{kg}$ \\
\hline Specific Energy Cost & 0.070 & 0.075 & 0.076 & 0.077 & 0.080 & 0.11 & THB/MJ \\
\hline Energy Saving & 0.04 & 0.03 & 0.03 & 0.03 & 0.03 & - & THB/MJ \\
\hline Energy Saving Cost/Unit & 1.06 & 0.90 & 0.90 & 0.86 & 0.79 & - & $\mathrm{THB} / \mathrm{kg}$ \\
\hline Disposal Cost/Unit & 0.00 & 0.50 & 0.65 & 0.75 & 1.00 & - & $\mathrm{THB} / \mathrm{kg}$ \\
\hline Total Saving Cost/Unit & 1.06 & 1.40 & 1.55 & 1.61 & 1.79 & - & $\mathrm{THB} / \mathrm{kg}$ \\
\hline Total Saving Cost & 9,285 & 12,306 & 13,552 & 14,068 & 15,657 & - & THB/Yrs \\
\hline \%Total Saving & 35.33 & 46.83 & 51.57 & 53.53 & 59.58 & - & $\%$ \\
\hline NPV & $-32,910$ & 6,050 & 21,142 & 28,057 & 48,328 & - & ТНВ \\
\hline IRR & N/A & 4.97 & 15.41 & 19.67 & 31.19 & - & $\%$ \\
\hline $\mathrm{B} / \mathrm{C}$ & 73.83 & 105.17 & 118.48 & 124.91 & 144.64 & - & $\%$ \\
\hline Payback Period & N/A & 7.94 & 4.98 & 4.74 & 3.00 & - & Yrs. \\
\hline
\end{tabular}




\subsection{Economic analysis}

Various ratios of rice straw and sewage sludge (RS: SS) pellets were analyzed for calorific value to determine the combustion energy available from co-pelletization. They can be used as a substitute for coal, which is a commonly used fuel. This energy value can be used to analyze the economic return from the use of co-pelleted sewage sludge and rice straw. The investment costs (pellet machine and maintenance cost), benefits, and analysis of the processing cost (material, operating, heating value, and disposal cost) of co-pelletization with various ratios are summarized in Table 5.

Table 5 and Fig. 7 show an analysis of the economic returns of co-pelletization in various proportions. The use of co-pellets yields two financial benefits and cost savings for sewage sludge disposal. They are used as raw materials for the manufacture of co-pellets and as fuel in boilers, resulting in reduced coal consumption. From Fig. 9 , it can be concluded that the utilization of a higher copelletization proportion of sewage sludge resulted in a higher economic value. This suggests that the co-pellet with a ratio of RS0:SS100 of sewage sludge provides the best economic returns as follows: total saving cost 59.58\%, NPV 48,328.03 THB (USD 1,610.93), IRR 31.19\%, and B/C $144.64 \%$, at a payback period of three years. The results of the analysis were similar to those of (Pradhan et al., 2019). The proposed concept of their research integrates gasification and pelletization technologies. Their results suggested that the production pellet capacity of $500 \mathrm{~kg} / \mathrm{h}$ was economically acceptable, and the IRR, NPV, and discounted payback period were 41\%, (USD 130,000 ₹9.35 million), and 2.8 yrs.

The results indicate a balance between a cost analysis of co-pelletization and an improvement in pelletization fuel. Therefore, co-pellets could be a suitable solid fuel for industrial use.

\subsection{Environmental analysis}

A possibility for sewage sludge management is the reuse of waste from the wastewater treatment plant as a material for co-combustion in industries to reduce sewage sludge to landfill. The utilization of sewage sludge is widely recognized because these wastes have low sulfur content, resulting in low sulfur by-products $\left(\mathrm{SO}_{\mathrm{x}}\right)$ with increased excess air (Vamvuka et al., 2019). By recycling, the tuna waste by-product can be utilized in the feed mill industry.

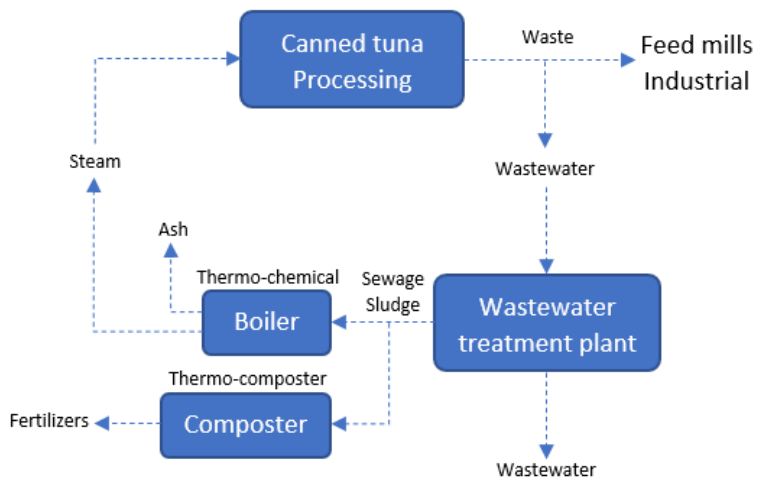

Fig. 8 Sewage sludge management cycle
In terms of sewage sludge treatment, the by-products obtained can be further utilized in industries for resource and energy recovery (Fig. 8).

Furthermore, ash from sewage sludge combustion can be used in the construction industry (Smol et al., 2015). In terms of thermo-composter treatment of sewage sludge, using sewage sludge as a fertilizer significantly increases plant nutrients. Another management method is to replace fertilization with natural fertilizers or utilize as supplementary fertilization (Anna et al., 2019).

\section{Conclusions}

The co-pelletization of sewage sludge and rice straw (agricultural waste) was studied in a specified proportion to produce co-pellets. These wastes pass through the preparation and forming process, which allows storage without causing secondary environmental pollution and facilitates transportation, which increases its potential application. An appropriate ratio of sludge components can be used as natural binders. The optimized co-pellets for this purpose was obtained at an SS:RS ratio of $50 \%$ (SS50\%). However, to determine the duration of storage, further research is needed to study the strength properties of the co-pellets. The most beneficial co-pellets in energy production are those from pure rice straw (RS100:SS0). From the economic analysis, it is suggested that the utilization of a higher co-pelletization proportion of sewage sludge resulted in greater economic gains. The high proportion of sewage sludge resulted in a benefit from the sewage sludge disposal cost of $1 \mathrm{THB} / \mathrm{kg}$ (USD/kg 0.033) and higher economic returns. Environmentally, these wastes have low sulfur content, resulting in low sulfur by-products $\left(\mathrm{SO}_{\mathrm{x}}\right)$, which are suitable for solid fuel production. Nevertheless, there is still a high ash residue, and consequently, the management of the ash must be considered further. The utilization of these wastes develops sustainability and reduces negative impacts due to disposal by landfill. Therefore, rice straw-sludge mixed pellets could be a suitable solid fuel for industrial use.

\section{Acknowledgements}

The authors thank the National Metal and Materials Technology Center (MTEC) for providing the shredder for preparing the rice straw feedstock. We also thank King Mongkut's University of Technology Thonburi (KMUTT) for supporting the Bomb calorimeter.

\section{References}

Abraham, A., Mathew, A. K., Sindhu, R., Pandey, A., \& Binod, P. (2016). Potential of rice straw for bio-refining: An overview. Bioresource technology, 215, 29-36. https://doi.org/10.1016/j.biortech.2016.04.011

Anna, G., Anna, G., Małgorzata, K., Tomasz, K. (2019). Sewage sludge processing and management in small and mediumsized municipal wastewater treatment plant-new technical solution. Journal of Environmental Management, 234, 90-96. https://doi.org/10.1016/j.jenvman.2018.12.074

Biswas, B., Singh, R., Kumar, J., Singh, R., Gupta, P., Krishna, B. B., \& Bhaskar, T. (2018). Pyrolysis behavior of rice straw under carbon dioxide for production of bio-oil. Renewable 
Energy,

129 ,

686-694

https://doi.org/10.1016/j.renene.2017.04.048

Dávid, N., Péter, B., Zoltán, G., József, P., Judit , O., \& Attila, B. (2018). Economic Analysis of Pellet Production in CoDigestion Biogas Plants. Energies, 11(5), 1135 https://doi.org/10.3390/en11051135

Dessbesell, L., Welter, CA., de Farias, JA. (2019). Economic and Environmental Analysis of Pellets' Production in Rio Pardo Watershed, Brazil. Floresta e Ambiente, 26(4), e20160427. https://doi.org/10.1590/2179-8087.042716

El-Qelish, M., Chatterjee, P., Dessì, P., Kokko, M., El-Gohary, F., Abo-Aly, M., \& Rintala, J. (2019). Bio-hydrogen Production from Sewage Sludge: Screening for Pretreatments and Semicontinuous Reactor Operation. Waste and Biomass Valorization. https://doi.org/10.1007/s12649-019-00743-5

Fu, P., Hu, S., Xiang, J., Sun, L., Su, S., \& Wang, J. (2012). Evaluation of the porous structure development of chars from pyrolysis of rice straw: Effects of pyrolysis temperature and heating rate. Journal of Analytical and Applied Pyrolysis, 98, 177-183. https://doi.org/10.1016/j.jaap.2012.08.005

Gao, N., Kamran, K., Quan, C., \& Williams, P. T. (2020). Thermochemical conversion of sewage sludge: A critical review. Progress in Energy and Combustion Science, 79, 100843. https://doi.org/10.1016/j.pecs.2020.100843

Grobelak, A., Grosser, A., Kacprzak, M., \& Kamizela, T. (2019). Sewage sludge processing and management in small and medium-sized municipal wastewater treatment plant-new technical solution. Journal of Environmental Management, 234, 90-96, https://doi.org/10.1016/j.jenvman.2018.12.111

Guerard, F., Guimas, L. \& Binet, A. (2002). Production of tuna waste hydrolysates by a commercial neutral protease preparation. Journal of Molecular Catalysis B: Enzymatic, 19-20, 489-498. https://doi.org/10.1016/S1381-1177(02)002035

Guzmán A, Á., Delvasto A, S., \& Sánchez V, E. (2015). Valorization of rice straw waste: an alternative ceramic raw material. Cerâmica, 61, 126-136. https://doi.org/10.1016/j.jenvman.2018.12.111

He, C., Tang, C., Liu, W., Dai, L., \& Qiu, R. (2020). Co-pyrolysis of sewage sludge and hydrochar with coals: Pyrolytic behaviors and kinetics analysis using TG-FTIR and a discrete distributed activation energy model. Energy Conversion and Management, 203 ,

112226. https://doi.org/10.1016/j.enconman.2019.112226

Hossain, N., \& Morni, N. A. H. (2020). Co-pelletization of Microalgae-Sewage Sludge Blend with Sub-bituminous Coal as Solid Fuel Feedstock. BioEnergy Research, 13(2), 618-629. https://doi.org/10.1007/s12155-019-10061-2

Hsu, K.C., Lu, G.H. \& Jao, C.L. (2009). Antioxidative properties of peptides prepared from tuna cooking juice hydrolysates with orientase (Bacillus subtilis). Food Research International, $\quad 42, \quad 647-652$. https://doi.org/10.1016/j.foodres.2009.02.014

Huang, H.-j., Yang, T., Lai, F.-y., \& Wu, G.-q. (2017). Co-pyrolysis of sewage sludge and sawdust/rice straw for the production of biochar. Journal of Analytical and Applied Pyrolysis, 125, 6168. https://doi.org/10.1016/j.jaap.2017.04.018

Jiang, L., Liang, J., Yuan, X., Li, H., Li, C., Xiao, Z., Zeng, G. (2014). Co-pelletization of sewage sludge and biomass: The density and hardness of pellet. Bioresource Technology, 166, 435-443. https://doi.org/10.1016/j.biortech.2014.05.077

Jiang, L., Yuan, X., Xiao, Z., Liang, J., Li, H., Cao, L., Zeng, G. (2016). A comparative study of biomass pellet and biomasssludge mixed pellet: Energy input and pellet properties. Energy Conversion and Management, 126, 509-515. https://doi.org/10.1016/j.enconman.2016.08.035

Kim, B., Gautier, M., Michel, P., \& Gourdon, R. (2013). Physicalchemical characterization of sludge and granular materials from a vertical flow constructed wetland for municipal wastewater treatment. Water Sci Technol, 68(10), 2257-2263. https://doi.org/10.2166/wst.2013.485

Kowalski, M., Kowalska, K., Wiszniowski, J., \& Turek-Szytow, J. (2018). Qualitative analysis of activated sludge using FT-IR technique. Chemical Papers, 72(11), 2699-2706. https://doi.org/10.1007/s11696-018-0514-7

Krueger, B. C., Fowler, G. D., Templeton, M. R., \& Moya, B. (2020). Resource recovery and biochar characteristics from full-scale faecal sludge treatment and co-treatment with agricultural waste. Water Research, 169, 115253. https://doi.org/10.1016/j.watres.2019.115253

Kwapinska, M., Horvat, A., Liu, Y., \& Leahy, J. J. (2020). Pilot Scale Pyrolysis of Activated Sludge Waste from Milk Processing Factory. Waste and Biomass Valorization, 11(6), 2887-2903. https://doi.org/10.1007/s12649-019-00596-y

Lisowski, A., Matkowski, P., Dąbrowska, M., Piątek, M., Świętochowski, A., Klonowski, J., Reshetiuk, V. (2020). Particle Size Distribution and Physicochemical Properties of Pellets Made of Straw, Hay, and Their Blends. Waste and Biomass Valorization, 11(1), 63-75. https://doi.org/10.1007/s12649-018-0458-8

Matthews, S. (2016). Structural Changes of Rice Straw PreTreated with Paenibacillus and Aspergillus fumigatus (Vol. 5). International Journal of Agricultural and Food Research, 5(4). doi:10.24102/ijafr.v5i4.695

Park, J., Lee, Y., Ryu, C., \& Park, Y.-K. (2014). Slow pyrolysis of rice straw: Analysis of products properties, carbon and energy yields. Bioresource Technology, 155, 63-70. https://doi.org/10.1016/j.biortech.2013.12.084

Piyarath, S., Boonrod, S., Shabbir, H. G. (2020). Life Cycle Assessment of wood Pellet Production in Thailand. Sustainability, $12(17), \quad 6996$. https://doi.org/10.3390/su12176996

Pradhan, P., Gadkari, P., Mahajani, S. M., \& Arora, A. (2019). A conceptual framework and techno-economic analysis of a pelletization-gasification based bioenergy system. Applied Energy, 249 , https://doi.org/10.1016/j.apenergy.2019.04.129

Racek, J., Sevcik, J., Chorazy, T., Kucerik, J., \& Hlavinek, P. (2020). Biochar - Recovery Material from Pyrolysis of Sewage Sludge: A Review. Waste and Biomass Valorization, 11(7), 3677-3709; https://doi.org/10.1007/s12649-019-00679-w

Rungrodnimitchai, S. (2014). Rapid Preparation of Biosorbents with High Ion Exchange Capacity from Rice Straw and Bagasse for Removal of Heavy Metals. The Scientific World Journal, 2014, 634837. https://doi.org/10.1155/2014/634837

Scatolino, M. V., Neto, L. F. C., Protásio, T. d. P., Carneiro, A. d. C. O., Andrade, C. R., Guimarães Júnior, J. B., \& Mendes, L. M. (2018). Options for Generation of Sustainable Energy: Production of Pellets Based on Combinations Between Lignocellulosic Biomasses. Waste and Biomass Valorization, 9(3), 479-489. https://doi.org/10.1007/s12649-017-0010-2

Smol, M., Kulczycka, J., Henclik, A., Gorazda, K., Wzorek, Z. (2015). The possible use of sewage sludge ash (SSA) in the construction industry as a way towards a circular economy. $J$. Clean. Prod. 95, 45e54. https://doi.org/10.1016/j.jclepro.2015.02.051.

Sultanbawa, Y. \& Aksnes, A. (2006). Tuna process waste - an unexploited resource. INFOFISH International, 3, 37-40.

Vamvuka, D., Alexandrakis, S., \& Galetakis, M. (2019). Combustion Performance of Sludge From a Wastewater Treatment Plant in Fluidized Bed. Factorial Modeling and Optimization of Emissions. Frontiers in Energy Research, 7(43), doi:10.3389/fenrg.2019.00043

Yilmaz, E., Wzorek, M., \& Akçay, S. (2018). Co-pelletization of sewage sludge and agricultural wastes. Journal of Environmental Management, 216, 169-175. https://doi.org/10.1016/j.jenvman.2017.09.012

Zhao, X.-g., Jiang, G.-w., Li, A., \& Wang, L. (2016). Economic analysis of waste-to-energy industry in China. Waste Management, https://doi.org/10.1016/j.wasman.2015.10.014

Zhou, L., Gao, Y., Yu, K., Zhou, H., De Costa, Y. G., Yi, S., \& Zhuang, W.-Q. (2020). Microbial community in in-situ waste sludge anaerobic digestion with alkalization for enhancement of nutrient recovery and energy generation. Bioresource Technology, 295, 122277; 
Citation: Duangjaiboon, K., Kitiwan., M., and Kaewpengkrow, P.R. (2021) Co-pelletization of Industrial Sewage Sludge and Rice Straw: An Environmental and Economic Analysis. Int. Journal of Renewable Energy Development, 10(3), 653-662, doi: 10.14710/ijred.2021.33834

$\mathrm{P}$ a g e $\mid 662$

Zhu, X., Zhao, L., Fu, F., Yang, Z., Li, F., Yuan, W., Zhang, X. (2019). Pyrolysis of pre-dried dewatered sewage sludge under different heating rates: Characteristics and kinetics study. Fuel, 255, 115591. https://doi.org/10.1016/j.fuel.2019.05.174 